\title{
Baahubali: The Beginning, a Hamlet in Indian Movie
} Jian Wang ${ }^{1}$, Lulu Chen ${ }^{2}$, and Yuanyuan Cai ${ }^{3}$

'Zaozhuang University, College English Department, Zaozhuang, Shandong, 277160;

${ }^{2}$ Procuratorate of Shizhong District, Investigation and Supervision Department, Zaozhuang, Shandong, 277100;

${ }^{3}$ Zaozhuang Experimental School, Zaozhuang, Shandong, 277000

\begin{abstract}
In 2015, "Baahubali: The Beginning" as India's largest investment in the film history , with its grand scenes and dazzling special effects to conquer the audience, has made remarkable reputation and box office. The film unveils Shivudu's life story, and sets an ambush for its companion film "Baahubali: final" which will show us Baahubali's revenge for his father. This movie makes people think of Shakespeare's "Hamlet": Uncle Claudius usurps the throne, the prince takes a revenge for his father, therefore, many viewers call this movies "Baahubali: The Beginning" as the Indian version of "Hamlet."
\end{abstract}

Keywords: Baahubali; Revenge; Hamlet; Mahabharata; India movie

\section{《巴霍巴利王》印度电影中的王子复仇记}

王健 ${ }^{1}$, 陈璐璐 ${ }^{2}$, 蔡媛媛 ${ }^{3}$

(1.本庄学院、大学英语教学部，山东本庄 $277160 ； 2$. 本庄市市中区检察院侦查监督科，山 东本庄 277100；3. 本庄实验学校，山东 柬庄 277000）

摘要: 上映于 2015 年的《巴霍巴利王-开端》作为印度电影史上投资最大的电影, 以其宏大的场面和炫目的特效征服了 观众, 取得了骄人的口碑和票房。故事揭开了 Shivudu的身世, 片尾设下埋伏, 为其姊妹篇《巴霍巴利王一终篇》做好了为 其父 Baahubali 复仇的铺垫。这部电影让人不免联想到莎士比亚的《哈姆雷特》: 叔父篡权夺位, 王子为父报仇, 因此, 很 多观影人将其誉为印度版的《王子复仇记》。

关键词: 巴霍巴利王子复仇记哈姆雷特摩诃婆罗多印度电影

中图分类号: I106.3 文献标志码: A

引言

作为印度电影有史以来投资最大（制作耗资 17 亿 5 千万卢比，约合 1 亿 6975 万人民币）的史诗巨制, 《巴霍巴利王-开端》（2015）以其恢弘的战争场面及沈人心扉的特效令观影人印象深刻。深受好莱坞影响 的导演 S. S. Rajamouli 将这部史诗巨作拍得叙事连贯流畅、场面气势磅礴、歌舞也恰到好处, 无论是口 碑还是票房都有斩获, 该片堪称宝莱坞电影史上的一部里程碑。故事以一个被收养长大的名叫 Shivudu 的 部落男孩开头, 讲述他在好奇心和勇气的驱使下, 离开山谷, 攀爬瀑布追寻漂亮姑娘 Tamanna; 一系列的 遭遇让他见到了 Mahishmati 王国叛乱后被囚禁的亲生母亲 (Devasena), 从奴隶侍卫长 Kattappa 口中慢 慢了解到自己不同寻常的身世: 英明的国王父亲 Amarendra Baahubali 被杀害, 残忍的凶手正是叔叔 Bhallaladeva。作为该剧的姊妹篇《巴霍巴利王-终篇》定于 2016 年上映, 故事将延续前部, 继续讲述宫 廷争斗及 Shivudu 的复仇。两部涉及王权争夺、宫廷争斗、叔伯串位的电影, 让观影人俨然看到了一部印 度版的《王子复仇记》。 


\section{1 相似的王子复仇记}

真正的《王子复仇记》，即莎士比亚的《哈姆雷特》故事情节取材于丹麦八世纪的史实，该书成篇于 十七世纪初, 该剧背景设置在中世纪, 讲述了一个丹麦王子哈姆雷特为父报仇的故事, 深刻再现了文艺复 兴的晚期英国和欧洲社会的社会现实，体现了莎士比亚对欧洲文艺复兴运动的深刻思考及关注。

《巴霍巴利王》和《哈姆雷特》虽为不同时期，不同国家的两部作品，但是两个故事有很多类似的地 方, 无论是叔父篡权的阴谋、王子为父报仇的情节、还是悲剧情节的描写, 都不禁让观影人将两部作品定 义为 “王子复仇记”。

\section{1 叔父篡权夺位, 王子为父报仇}

《哈姆雷特》中叔父克劳迪斯斌杀王兄, 抢夺王位, 强娶兄嫂, 件件皆是大罪, 他败坏伦常, 残暴贪 淫, 狡猾阴险, 十足的两面派作风。哈姆雷特说他是：“一个冒充国王的丑角，一个盗国窃位的扒手，从 架子上偷下那项珍贵的王冠，塞进自己的腰包里。一个下流褴褛的国王 [1]。(第 3 幕第 4 场) ” 克劳迪 斯惯用奸计，是一个极其猥琐的统治者的形象。身背国恨家仇，哈姆雷特在危险的处境中装疯卖俊，被叔 父流放，被海盗抓获，费劲周折，最终与克劳迪斯同归于尽，为父报仇雪恨！

在《巴霍巴利王》中，作为 Shivudu 的叔父 Bhallaladeva，在王位争夺中，阴招尽使，三番五次置 Amarendra Baahubali 于死地, 追杀还在襁褓中 Shivudu, 并在广场上贝禁其生母多年, Bhallaladeva 王 过着歌舞升平的日子，剧中士兵无情地鞭打罪犯、国王横征百姓为其修建金像就是其暴君的最好诠释。第 一部《巴霍巴利王》是故事的开端和铺垫, 由于故事较长, Shivudu 为父报仇的过程被导演放在了《巴霍 巴利王一终篇》中展开, 可以预见的是, 在第二部中, Bhallaladeva 的篡权夺位将进一步显露, 男主角的 身世也将更加明晰, 其为父报仇的过程也将就此展开。相信这个过程将是充满艰辛, 阴谋和争斗仍将伴其 左右, 续篇将更为紧凑、更为精彩。

\section{2 王子受人爱戴, 复仇穿插爱情}

在巨大的灾难降临到哈姆雷特身上时, 他的人民还是非常欢迎他, 爱戴他。不论阶层, 不管是否喜欢, 哈姆雷特都能涁涁有礼, 表现出谦逊与和蔼: 不管是对军官还是士兵, 他总是以诚相待, 面对他们总是笑 容可掬, 称他们为朋友; 哈姆雷特同情百姓, 不赞成封建等级关系, 对待下层百姓平易近人，在人民群众 中有很高的威望; 他与士兵、仆人交往, 不摆王子的官架子, 得到了底层百姓的拥护和爱戴, 众人皆呼愿 意为殿下尽忠 $[2]$ 。

都说戏剧不能缺乏爱情。《哈姆雷特》中王子虽然背负着替父报仇, 为母雪耻, 为国除害的大任, 即 使在复仇的火海中挣扎, 即使她是波洛涅斯的女儿, 王子还是坠入了爱河。哈姆雷特曾经写信给奥菲利亚 来表白: “你可以疑心星星是火把; 你可以疑心太阳会转移; 你可以疑心真理是谎话; 可是我的爱永没有 改变 $[1]$ 。(第 2 幕第 2 场) ”

在《巴霍巴利王》中, 当 Shivudu 捡起绳索拖住摇摇欲坠的叔父金像, 奴隶们看到他大呼 “巴霍巴利” 的时候; 当敌人把平民放在阵前充当挡箭牌, 而 Baahubali 王（与 Shivudu 均为一人扮演）宁肯贻误战机 采用变通的方式进攻, 却不肯伤害无辜百姓, 而这恰与 Bhallaladeva 开着旋桨战车将阵前百姓斩杀马下 形成了鲜明的对比，我们看到了人们对于巴霍巴利王的爱戴和他对于百姓的爱护。

《巴霍巴利王-开端》虽为宫廷复仇电影, 导演对 Shivudu 的爱情还是不吝篇幅的。男主角追逐飘渺 
的 Tamanna 攀爬到从小就难以逾越的瀑布顶端, 见证爱情力量的伟大。可以说是 Tamanna 指引着 Shivudu 去发现、去探索自己的身世。当 Shivudu 为 Tamanna 纹上漂亮的花朵、送还属于她的面具, 爱情由此滋生; 这也使得随后出现的男女主角的歌舞较之其余印度电影那不合时宜的唱跳场面显得更顺其自然、不显突 兀。

\section{3 复仇成功与否, 同为历史悲剧}

哈姆雷特为父报仇过程中, 错杀奥菲莉亚的父亲波罗涅斯, 之后奥菲莉亚自杀, 哈姆雷特不得不接受 与其兄雷欧提斯的决斗。克劳迪斯为哈姆雷特准备的毒酒在决斗中不幸被王子的母亲乔特鲁德所喝而死 去, 雷欧提斯和哈姆雷特王子两人也中了毒剑, 临死前得知个中原委的哈姆雷特杀死了克劳迪斯, 他叮嘱 朋友霍拉旭把自己不幸的故事转告后人。《哈姆雷特》以悲剧告终令人一目了然, 而我们也要看到, 在 17 世纪的封建宫廷中, 哈姆雷特王子是涌现出来的为数不多的先进人物的典型, 思想先进, 代表时代潮流, 他与罪恶叔父为首的宫廷内斗，反映了文艺复兴时期具有资产阶级思想的人物为实现自身理想与固守封建 思想的社会邪恶力量所进行的斗争。但是, 在这样的时代中, 封建恶势力肆虐, 黑白不分, 资产阶级的人 文主义的理想实现起来无疑是困难重重。一如社会形态交替之际, 稚嫩的先进力量与强大的顽固旧势力之 间的矛盾难以调和, 悲剧性的冲突难以避免。所以可以说, 哈姆雷特的悲剧也是那个时代的悲剧。

《巴霍巴利王-开端》作为姊妹电影的先行者, 并没有为观影人将故事完全铺开, 电影最后一幕奴隶 侍卫长 Kattappa 从背后刺杀 Amarendra Baahubali 王, 为第二部《巴霍巴利王-终篇》做好了铺垫。王子 如何复仇、主人公命运几何、影片如何剧终、这到底是一部王子复仇的正剧还是悲剧, 恐怕只有在第二部 上映时才能揭开谜底。为了更好地欣赏这部影片, 观影人更应该从这部电影的出处去考虑。导演兼编剧兼 制片人 S. S. Rajamouli 在接受 India Express 采访时直言, 《罗摩衍那》和《摩诃婆罗多》两部作品从小 就滋养着他, 是其电影创作思想的源泉; 《摩诃婆罗多》中般度五子和持国百子史诗般的战争是《巴霍巴 利王》电影中气势恢弘战争场面的重要灵感来源。而《摩诃婆罗多》正是我们了解这部电影的的关键。

《摩诃婆罗多》从婆罗多族后裔、象城国王福身王讲起，围绕其子孙俱卢族与般度族之间的王位争夺 展开。现代印度人将《摩诃婆罗多》认为是本民族的史诗, 这部作品里面的很多故事和人物都是印度人民 所熟知的。印度人虽然不能直接读懂梵语的原文, 但是从日常生活的迎神赛会, 节日的史诗演唱中, 从众 多的诗歌、喜剧、舞蹈和其他文学艺术形式中, 从现代语言的翻译本、改写本中, 仍能耳濡目染它的内容。 《摩诃婆罗多的故事》这部书的作者拉贾戈帕拉查理在英文第三版的序言中说: “一个人旅行全印度, 看 到了一切东西, 可是除非他读了《罗摩衍那》和《摩诃婆罗多》, 他不能了解印度的生活方式。[3]” (序 言 金克木, 2007:4) 可见 《摩诃婆罗多》的人文影响是多么巨大, 正如《论语》之于中国人。要想更多 地看懂印度电影, 不了解这两部作品, 显然是困难的。很多在观影人看来难于理解的情节, 在印度人看来, 都是他们民族耳熟能详的故事了。《摩诃婆罗多的故事》中这样说: “《摩诃婆罗多》只是成为无数作品 的泉源, 枝枝节节地供后来人利用。[3]”（序言 金克木 2007:3）所以我们要跳出这部电影来看戏剧本身 的性质。

《摩诃婆罗多》的成书时间历时八百余年 (约从公元前四世纪至公元四世纪)。这部作品长期通过口 头叙述的方式加以创作和流传, 内容得到不断地扩充, 长期积累而得以成型。它的成书年代处在印度历史 转型时期, 即从部落社会形态逐渐蜕变为国家社会形态的时代, 也是从吠陀时期的婆罗门教转化为史诗时 
期的新婆罗门教（即印度教）的时代。这部史诗以印度列国纷争的时代为背景, 讲述了一部同宗骨肉为王 权展开的同室操戈的流血史, 大战中双方虽然都有胜败, 但不幸的是同族将士几乎悉数为宫廷内斗英勇牺 牲, 无疑也是一个历史悲剧。

\section{2 不同的王子复仇记}

除去两部作品相同的王子复仇情节外衣, 我们也应该看到, 两部作品在历史意义及写作诉求上有着很 多的不同。

《哈姆雷特》虽是描写丹麦八世纪的历史, 但却是十六世纪末和十七世纪初的英国的社会现实的真实 写照。当时的英国可谓一个 “颠倒混乱的时代” , 而《哈姆雷特》正是整个时代的一个缩影。剧中哈姆 雷特与叔父克劳迪斯的斗争, 象征着具有人文主义的新兴资产阶级与墨守成规的反动封建王权代表之间的 斗争。戏剧凸显了英国人文主义理想同黑暗的封建现实之间的矛盾, 揭露了十七世纪交替之际, 英国封建 贵族地主阶级与新兴资产阶级之间权利争夺的社会现实。

《巴霍巴利王》编剧灵感取自《摩诃婆罗多》, 后者这部伟大的印度史诗所写的故事不是一般的王族 内争, 而是宫廷内部相互对立的两类统治者之间的内部斗争, 没有差异的相同阶级之间的斗争, 史诗描述 了惨遭流放迫害的一方, 遭受凌辱, 以弱小的力量对抗高居王位、骄横残暴的强权斗争。作品颂扬了代表 正义力量的坚战一方, 谴责了代表邪恶势力的难敌一方。坚战方公正、谦恭、仁慈, 而难敌方贪婪、傲慢、 残忍。史诗反映乱世下的人民盼望摆脱残暴君主的统治、渴望圣贤君主一统天下的美好愿望, 反映的是封 建王权内部的争斗。

\section{3 结论}

一部印度电影《巴霍巴利王-开端》让许多观影人产生了《王子复仇记》的即视感, 王权被叔父所夺, 王子生母一个被叔父囚禁, 一个被叔父所娶; 王子为雪耻国恨家仇, 同叔父斗智斗勇, 展开抗争; 电影中 不乏对王子爱民特点以及爱情的描写, 两部同为历史悲剧的王子复仇电影, 太多相似的情节和片段让观影 人将它定义为印度版的《哈姆雷特》也就不足为奇了。在看到二者诸多相似点的同时, 观影人也需要认识 到: 写作背景的不同, 使得两部作品在诉求和历史意义上必然产生不一样的影响。《巴霍巴利王》取材于 印度著名史诗《摩诃婆罗多》, 反映的是封建制度下人们追寻贤明君主的愿望; 而莎士比亚的《哈姆雷特》 成书于新兴资产阶级萌芽时期, 主要诉求在于揭露封建贵族的腐朽和没落。

\section{参考文献:}

[1] William Shakespeare, 朱生豪译. 哈姆雷特[M].湖北教育出版社, 1998.

[2] 段风丽. 试论《哈姆雷特》的悲剧性 [J]. 课程教育研究, 2014(10):90

[3] 拉贾戈帕拉查理, 唐季雍译. 摩诃婆罗多的故事 [M].三联书店, 2007.

[4] 毗耶乷, 黄宝生等译. 摩诃婆罗多 [M]. 中国社会科学出版社, 2005 .

\section{References:}

[1] WilliamShakespeare, Zhu Shenghao translation. Hamlet [M].Hubei Education Press, 1998.

[2] Duan Fengli. Discussion on the tragedy of Hamlet [J].Curriculum Education Research, 2014(10):90

[3] Rajagopalachari, Tang Jiyong translation. Story of the Mahabharata [M].Joint Publishing, 2007.

[4] Vyāsa, Huang Baosheng, et al. Mahabharata [M].China Social Sciences Press, 2005. 